\title{
TIMI, GRACE and alternative risk scores in Acute Coronary Syndromes: A meta-analysis of 40 derivation studies on 216,552 patients and of 42 validation studies on 31,625 patients
}

\author{
Fabrizio D'Ascenzo ${ }^{\text {a,* }}$, Giuseppe Biondi-Zoccai ${ }^{b}$, Claudio Moretti ${ }^{\text {a }}$, Mario Bollati ${ }^{\text {a }}$,

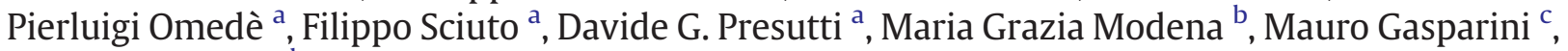 \\ Matthew J. Reed ${ }^{d}$, Imad Sheiban ${ }^{a}$, Fiorenzo Gaita ${ }^{a}$ \\ a Division of Cardiology, University of Turin, Turin, Italy \\ ${ }^{\mathrm{b}}$ Division of Cardiology, University of Modena and Reggio Emilia, Modena, Italy \\ ${ }^{c}$ Department of Mathematics, Politecnico di Torino, Italy \\ d Emergency Medicine Research Group Edinburgh (EMeRGE), United Kingdom
}

\section{A R T I C L E I N F O}

\section{Article history:}

Received 10 September 2011

Received in revised form 20 December 2011

Accepted 3 January 2012

Available online 11 January 2012

\section{Keywords:}

Acute coronary syndrome

Risk score

Meta-analysis

Prognosis

Percutaneous coronary revascularization

Surgical coronary revascularization

Systematic review

\begin{abstract}
A B S T R A C T
Background: Acute coronary syndromes (ACS) represent a difficult challenge for physicians. Risk scores have become the cornerstone in clinical and interventional decision making. Methods and results: PubMed was systematically searched for ACS risk score studies. They were divided into ACS studies (evaluating Unstable Angina; UA, Non ST Segment Elevation Myocardial Infarction; NSTEMI, and ST Segment Elevation Myocardial Infarction; STEMI), UA/NSTEMI studies or STEMI studies. The c-statistics of validation studies were pooled when appropriate with random-effect methods. 7 derivation studies with 25,525 ACS patients and 15 validation studies including 257,654 people were formally appraised. Pooled analysis of GRACE scores, both at short (0.82; 0.80-0.89 I.C 95\%) and long term follow up (0.84; 0.82-0.87; I.C 95\%) showed the best performance, with similar results to Simple Risk Index (SRI) derivation cohorts at short term. For NSTEMI/UA, 18 derivation studies with 56,560 patients and 18 validation cohorts with 56,673 patients were included. Pooled analysis of validations studies showed c-statistics of $0.54(95 \% \mathrm{CI}=0.52-0.57)$ and $0.67(95 \% \mathrm{CI}=0.62-0.71)$ for short and long term TIMI validation studies, and $0.83(95 \% \mathrm{Cl}=0.79-9.87)$ and $0.80(95 \% \mathrm{CI}=0.74-0.89)$ for short and long term GRACE studies. For STEMI, 15 studies with 134,557 patients with derivation scores, and 17 validation studies with 187,619 patients showed a pooled c-statistic of $0.77(95 \% \mathrm{CI}=0.71-0.83)$ and $0.77(95 \% \mathrm{CI}=0.72-0.85)$ for TIMI at short and long term, and a pooled c-statistic of $0.82(95 \%$ $\mathrm{CI}=0.81-0.83)$ and $0.81(95 \% \mathrm{Cl}=0.80-0.82)$ for GRACE at short and long terms respectively. Conclusions: TIMI and GRACE are the risk scores that up until now have been most extensively investigated, with GRACE performing better. There are other potentially useful ACS risk scores available however these have not undergone rigorous validation. This study suggests that these other scores may be potentially useful and should be further researched.
\end{abstract}

(c) 2012 Elsevier Inc. All rights reserved.

\footnotetext{
* Corresponding author at: Division of Cardiology, University of Turin, S. Giovanni Battista "Molinette" Hospital, Corso Bramante 88-90, 10126 Turin, Italy. Tel.: + 39 03333992707; fax: + 390116336769.

E-mail address: fabrizio.dascenzo@gmail.com (F. D'Ascenzo).
}

\section{Introduction}

Acute coronary syndromes (ACS) represent a wide clinical spectrum, ranging from unstable angina (UA) to ST Elevation Myocardial infarction (STEMI). There is heterogeneity of 
diagnosis, treatment, and prognosis at different ends of this ACS spectrum [1,2].

The use and development of dedicated scores to discriminate patients at high risk of serious adverse events from low risk ones has been suggested and encouraged by many cardiology expert groups in order to allow accurate therapeutic and diagnostic decision making. [3] Risk assessment remains crucial as the benefits of more aggressive and costly treatments are greatest in patients at higher risk of adverse clinical events [4-6].

Much effort has therefore been put into designing risk scores for ACS patients. The two most commonly used being the Global Registry in Acute Coronary Events (GRACE) [4] and the Thrombolysis in Myocardial Infarction (TIMI) [7] scores. Both are derived from landmark ACS studies and have undergone wide prospective evaluation. More recently other scores have been designed to focus on clinical risk assessment and to improve the selection of patients for clinical and interventional procedures.

Despite the presence of many validation studies confirming the validity of GRACE and TIMI in multiple clinical settings, to our knowledge there has been no meta-analysis to systematically compare their discriminatory performance. We therefore aimed to undertake a systematic review to assess ACS risk evaluation scores in order to determine the most accurately performing.

\section{Methods}

Current guidelines, including the recent Preferred Reporting Items for Systematic reviews and Meta-Analyses (PRISMA) amendment to the Quality of Reporting of Metaanalyses (QUOROM) statement, as well as recommendations from The Cochrane Collaboration and Meta-analysis of Observational Studies in Epidemiology (MOOSE) were followed during the course of this work [6-10].

\subsection{Search strategy}

MEDLINE/PubMed was searched for relevant English language articles using established methods [21] and the standard use of wild cards (identified by *): acute coronary syndrome* AND risk score AND validation cohort AND english[lang] NOT (review[pt] OR editorial[pt] OR letter [pt]), or acute coronary syndrome AND risk score* AND derivation cohort AND english[lang] NOT (review[pt] OR editorial [pt] OR letter[pt]).

Abstracts from scientific meetings and references of all included studies were also searched and appraised.

\subsection{Study selection}

Retrieved citations were first screened independently by two unblinded reviewers (GBZ, FDA) at the title and/or abstract level, with disagreements resolved by consensus. The full text of all potentially relevant articles were then fully appraised using the following explicit selection criteria, which were piloted over the first 5 studies to ensure consistency and discrimination. Inclusion criteria were (all had to be met for inclusion): (i) Human studies, (ii) Studies investigating patients presenting to hospital with ACS (i.e.UA, NSTEMI and STEMI), (iii) Risk score derivation or validation studies (or both) and (iv) Studies appraising scores using multivariate analysis. Exclusion criteria were (any single one enough for exclusion): (i) Non-human setting, (ii) Duplicate reporting (in which case the manuscript reporting the largest sample of patients with ACS was selected, or if equal, the study with the largest number of overall patients), or (iii) studies reporting only multivariate predictors, without prediction score.

\subsection{Data extraction}

The following data were independently abstracted by two unblinded reviewers (GBZ, FDA) on pre-specified electronic forms, which were piloted over the first 5 studies to ensure consistency and discrimination, with disagreements resolved by consensus.

Studies were first divided according to ACS clinical presentation i.e. UA, NSTEMI and STEMI or UA/NSTEMI studies or STEMI studies. Information recorded included authors details, journal, year of publication, location of the study group, baseline, angiographic and procedural features, kind of revascularization (fibrinolysis, percutaneous coronary intervention, coronary artery bypass graft), short and long term rates of adverse events (including death, myocardial infarction, revascularization procedures and Major Adverse Cardiac Events; MACE), and risk score, with respective AUC (area under the curve), c-index or c-statistic with 95\% confidence intervals. End points evaluated were c-index of the derivation risk scores and their performance when tested in validation cohorts.

\subsection{Internal validity and quality appraisal}

The quality of included studies was independently appraised by two unblinded reviewers (GBZ, FDA), on prespecified electronic forms, which were piloted over the first 5 studies to ensure consistency and discrimination, with disagreements resolved by consensus.

Modifying the MOOSE item list in order to take into account the specific features of included studies [8], we separately abstracted and appraised study design, setting, data source and statistical methods for multivariable analysis, as well as, in keeping with The Cochrane Collaboration approach, the risk of analytical, selection, adjudication, detection and attrition bias (expressed as low, moderate, or high risk of bias, as well as incomplete reporting leading to inability to ascertain the underlying risk of bias).

\subsection{Data analysis and synthesis}

Continuous variables are reported as mean (standard deviation) or median (range). Categorical variables are expressed as $\mathrm{n} / \mathrm{N}$ (\%). Statistical pooling was performed according to a random-effect model with generic inverse-variance weighting and computing c-index of the validation scores with 95\% confidence intervals using RevMan 5 (The Cochrane Collaboration, The Nordic Cochrane Centre, and Copenhagen, Denmark). Sensitivity analysis was performed to appraise small study bias by graphically inspecting funnel plots (Figure A, appendix, 


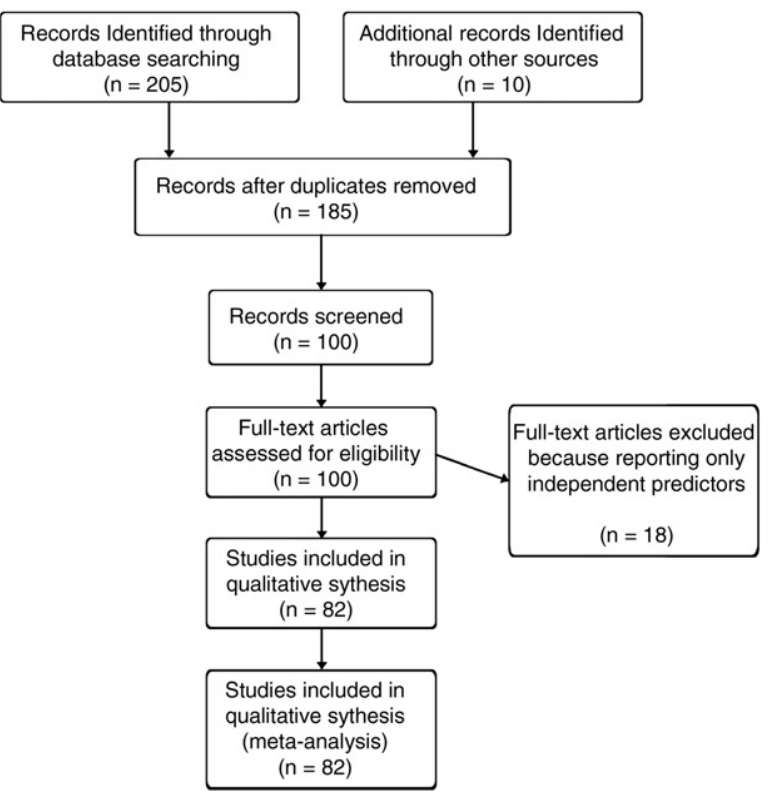

Fig. 1. Study flow diagram.

web only figure). The parallel fixed-effect model was also used to confirm our results.

\section{Results}

Data search and study selection are summarized in Fig. 1.

\subsection{ACS}

7 derivation studies [7,11-16] with 25,525 ACS patients and 15 validation studies [16-30] including 257,654 people were formally appraised. Baseline clinical features of included patients were similar (Table 1). The majority of patients were male. GRACE and SRI validation studies had a lower rate of Unstable Angina diagnosis and a higher rate of NSTEMI and STEMI diagnosis. Among all studies, about three quarters of patients underwent a percutaneous revascularization, with rates of MACE ranging from $4.7 \%$ to $11 \%$ and of death from $4.2 \%$ to $11 \%$. The short term TIMI AUC was 0.66 (95\% $\mathrm{CI}=0.64-0.68)$ and $0.73(95 \% \mathrm{CI}=0.69-$ 0.78 ) in derivation and validation cohorts respectively. GRACE short term derivation and validation AUC was 0.83 (95\% CI $=0.82-0.84)$ and $0.82(95 \% \mathrm{CI}=0.80-0.89)$. The Schiele et al. [16] score was the only one to perform similarly, with an AUC in the short term derivation cohort of 0.82 (95\% $\mathrm{CI}=0.80-0.82$ ). The long term AUC of the GRACE score was 0.84 , while for the Zhong et al. [15] score the AUC was 0.81 $(95 \% \mathrm{CI}=0.71-0.86)$.

\subsection{UA/NSTEMI}

18 derivation studies [7,11,20,31-45] with 56,560 UA/ NSTEMI patients and 18 validation cohorts [18,20,22,24,28, 30,32-36,46-52] with 56,673 patients were included. As in ACS studies, validation cohorts included more NSTEMI patients than derivation ones (Table 2), with rates of PTCA ranging from 26 to $48 \%$. Pooled analysis of TIMI validation studies showed an AUC of 0.54 (95\% $\mathrm{Cl}=0.52-0.57)$ and 0.67 (95\% $\mathrm{Cl}=0.62-$ 0.71 ) at short and long term. AUC was 0.83 (95\% CI $=0.79-$ 9.87) and 0.80 (95\% $\mathrm{CI}=0.74-0.89)$ for GRACE validation studies (Figs. 3 and 4). The short term AUC for the Correia et al. [33] study was $0.82(95 \% \mathrm{CI}=0.80-0.94)$ and for AMIS [20] was 0.87 ( $95 \% \mathrm{CI}=0.86-0.88)$. At long term no scores performed better than TIMI or GRACE, apart from several which had combined TIMI and GRACE with other variables.

\subsection{STEMI}

15 derivation studies [53-67] of 134,557 patients and 17 validation studies $[18,20,22,28,30,33,46,57,60,61,68-72]$ with 187,619 patients were included. Between 71 and $100 \%$ of patients underwent PCI, and PTCA (Table 3) was more frequently performed in validation cohorts than in derivation cohorts. AUC (Fig. 6) was 0.77 (95\% CI = 0.71-0.83) and 0.77 (95\% $\mathrm{CI}=0.72-0.85)$ for TIMI at short and long term, and $0.82(95 \%$ $\mathrm{CI}=0.81-0.83)$ and $0.81(95 \% \mathrm{CI}=0.80-0.82)$ for GRACE at short and long term. At short term, the CADILLAC score [59]

Table 1

Baseline characteristics ACS studies.

\begin{tabular}{|c|c|c|c|c|}
\hline & $\begin{array}{l}\text { Derivation studies } \\
{[7,11-16] \text { ( } 7 \text { studies, }} \\
25,535 \text { patients) }\end{array}$ & $\begin{array}{l}\text { TIMI validation studies } \\
{[17-25] \text { ( } 9 \text { studies, }} \\
127,383 \text { patients) }\end{array}$ & $\begin{array}{l}\text { GRACE validation studies } \\
{[16,18,21-23,25-30]} \\
\text { (11 studies, } 121,944 \text { patients) }^{*}\end{array}$ & $\begin{array}{l}\text { SRI }^{* *} \text { validation studies } \\
{[18,20,29] \text { ( } 3 \text { studies, }} \\
109,944 \text { patients) }^{*}\end{array}$ \\
\hline Patients & $1501(308-5940)$ & 703 (411-900) & $1057(722-1770)$ & $4223(900-1770)$ \\
\hline Male gender & $66(65-67)$ & $64(62-68)$ & $65(63-69)$ & $64.5(61.5-69)$ \\
\hline Age (years) & $65(61-69)$ & $63(61-66)$ & $65(63-66)$ & $67.5(65.3-66)$ \\
\hline Pts presenting with UA & $43(7-57)$ & $45(11-84)$ & $21(10-37)$ & $23(13.5-37)$ \\
\hline Pts presenting with NSTEMI & $43(32-45)$ & $31(12-41)$ & $41(30-43)$ & $40.5(37-43)$ \\
\hline Pts presenting with STEMI & $34(24-39)$ & $24(2.5-64)$ & $41(28-47)$ & $48(26.3-47)$ \\
\hline Pts undergoing PTCA & $77(63-88)$ & $66(62-69)$ & 65 (22-67) & $65(65-67)$ \\
\hline Pts undergoing $\mathrm{CABG}$ & $19(13-22)$ & $6(3-8.5)$ & $11(7.1-11)$ & $11(11-78)$ \\
\hline Follow up (days) & $90(30-365)$ & $60(30-292)$ & $181(112-244)$ & $315(290-244)$ \\
\hline Mace & $12(9-14)$ & $6(4-6.8)$ & $4.7(3.8-6.1)$ & $5(5-6.1)$ \\
\hline Death & $5(4-5.5)$ & $5(2.6-6.3)$ & $4.2(3.1-7.2)$ & $11(9-7.2)$ \\
\hline AMI & $2(2-5.5)$ & $3(2-4.5)$ & $1.05(0.6-1.5)$ & - \\
\hline
\end{tabular}

\footnotetext{
* Reported as median (1st; 3rd quartile) or $\mathrm{n} / \mathrm{N}$ (with patients or studies as denominators, as appropriate).

** Simple risk index.
} 
Table 2

Baseline characteristics of UA/NSTEMI studies.

\begin{tabular}{|c|c|c|c|c|}
\hline & $\begin{array}{l}\text { Derivation studies } \\
{[7,11,20,31-45]} \\
\text { (18 studies, } 56,560 \text { patients) }\end{array}$ & $\begin{array}{l}\text { TIMI validation studies } \\
{[18,20,24,33,35,36,46-51]} \\
\text { (12 studies, } 18,781 \text { patients) }\end{array}$ & $\begin{array}{l}\text { GRACE validation studies } \\
{[22,28,30,32-34,46-51]} \\
\text { (12 studies, } 36,517 \text { patients) }\end{array}$ & $\begin{array}{l}\text { Pursuit validation } \\
\text { studies }[49,52] \\
\text { ( } 2 \text { studies, } 2065 \text { patients) }\end{array}$ \\
\hline Patients & $540(440-2073)$ & $882(500-1001)$ & $1226(450-1770)$ & $1033(900-1770)$ \\
\hline Male gender & $66(65-68)$ & $61(60-67)$ & $65(63-69)$ & $65.5(61.5-69)$ \\
\hline Age (years) & $64.5(62-66)$ & $64(61-67)$ & $66(61-69)$ & $67.5(62-69)$ \\
\hline Pts presenting with UA & $54(39-68)$ & $41.5(27-70)$ & $40(23-52)$ & $22(11-33)$ \\
\hline Pts presenting with NSTEMI & $46(32-57)$ & $58.5(31-73)$ & $56(48-77)$ & $78(65-87)$ \\
\hline Pts undergoing PTCA & $27(21-33)$ & $48(35-51)$ & $26(22-38)$ & $27(20-33)$ \\
\hline Pts undergoing $\mathrm{CABG}$ & $13(12-27)$ & $12(7-5-12.5)$ & $8.5(6.5-9.5)$ & $8.5(6.7-8.8)$ \\
\hline Follow up (days) & $30(12-360)$ & $30(12-180)$ & $180(120-180)$ & $360(290-392)$ \\
\hline Mace & $30(14-60)$ & $8(6.5-9.7)$ & $5.8(4.2-8.2)$ & - \\
\hline Death & $4.7(3.4-11.4)$ & $7.5(5.3-11)$ & $7.5(7-14)$ & - \\
\hline AMI & $4.8(2.2-10)$ & $5(2.6-4.5)$ & $1.8(1.4-2.2)$ & - \\
\hline
\end{tabular}

had a comparable AUC as did studies by Chang et al. [54] (0.83; $95 \% \mathrm{CI}=0.82-0.84)$, Lee et al. [62] $(0.86 ; 9 \% \mathrm{CI}=0.84-0.86)$ and Peterson et al. [65] (0.90; 95\% CI=0.89-0.91). Long term AUC values for APEX AMI [66], PAMI [53], Khan et al. [61], Damman et al. [55] and Urbonaviciene et al. [67] studies were also good. These studies, are all showing comparable performance to TIMI and GRACE scores, are all derivation studies which have not yet been externally validated (Figs. 1-5). Results of studies reporting AUC values inferior to GRACE or TIMI are reported in Table $\mathrm{D}$, Appendix.

\section{Discussion}

The most important findings of our meta-analysis are: a) There is a striking difference in the rates of patients undergoing invasive revascularization between derivation and validation studies, b) TIMI and GRACE risk scores are the only scores which have been validated in all types of ACS, with the GRACE score performing better, c) many other risk scores, which show good performance in a derivation cohort, have not yet been evaluated in validation cohorts.

Derivation and validation studies evaluated in our review are quite heterogeneous from a methodological point of view. While about half of derivation studies consist of data derived from randomized clinical trials, almost all validation study data came from observational registries, most of them located in Europe and in North America. The application of data from highly selected cohorts to everyday life may undermine the reproducibility of these scores.

Patients in all studies are similar in baseline characteristics, with some differences in the rate of revascularization procedures. This was especially marked in studies evaluating UA/ NSTEMI or STEMI alone with higher revascularization rates in validation cohorts. It is worth noticing that, apart from STEMI patients, and despite recent guidelines no more than half of overall patients have undergone percutaneous or surgical revascularization, with an important burden of unfavorable effects, both for short and long term outcomes, as recently demonstrated $[73,74]$. The effect of these management strategies in derivation cohorts could also affect variables resulting in independent predictors of adverse events, thus underlying the need of new scores using more contemporary databases.

Our work confirms that TIMI and GRACE risk scores are the only ones validated in multiple clinical setting, with GRACE showing a better performance with an AUC around 0.85. In all the studies, the highest AUC values are around 0.85 . This is a satisfactory performance when compared to clinical scores for other medical conditions. [75-77]. For

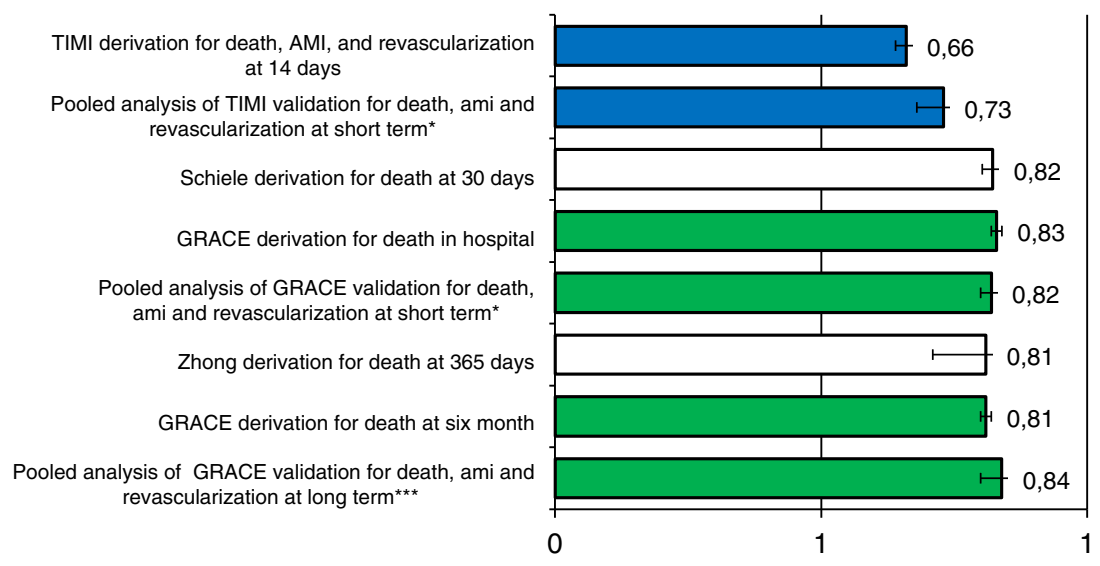

Fig. 2. Short and long term Area Under the Curve for derivation and validation scores of ACS. For scores other than TIMI and GRACE, only those with a performance better than the latter were reported. (*in hospital and 30 days follow up; ** 185 days (158-234); *** 180 days (180-360)). Heterogeneity for pooled results: $\mathrm{Tau}^{2}=0.00 ; \mathrm{Chi}^{2}=79.53, \mathrm{df}=6(P<0.00001) ; \mathrm{I}^{2}=92 \%$. 


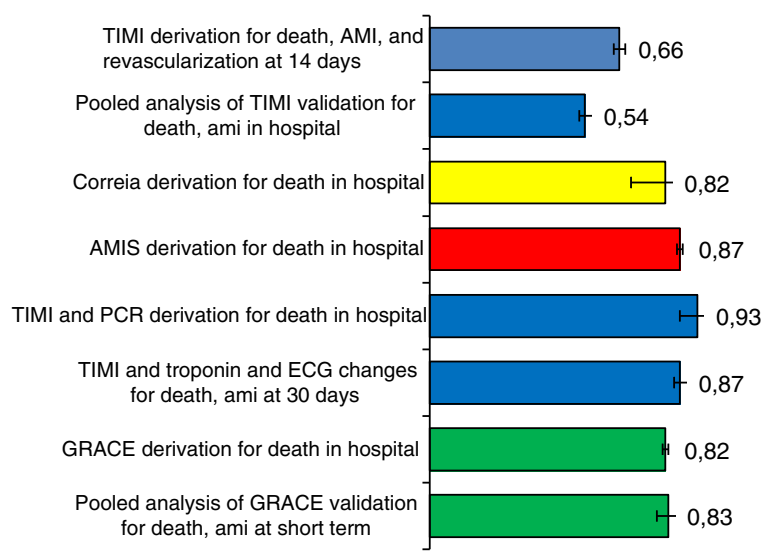

Fig. 3. Short term Area Under the Curve for derivation and validation scores of UA/NSTEMI. For scores other than TIMI and GRACE, only those with a performance better or equal than the latter were reported. Heterogeneity for pooled results: $\mathrm{Tau}^{2}=0.00 ; \mathrm{Chi}^{2}=0.02, \mathrm{df}=2(P=0.99) ; \mathrm{I}^{2}=0 \%$.

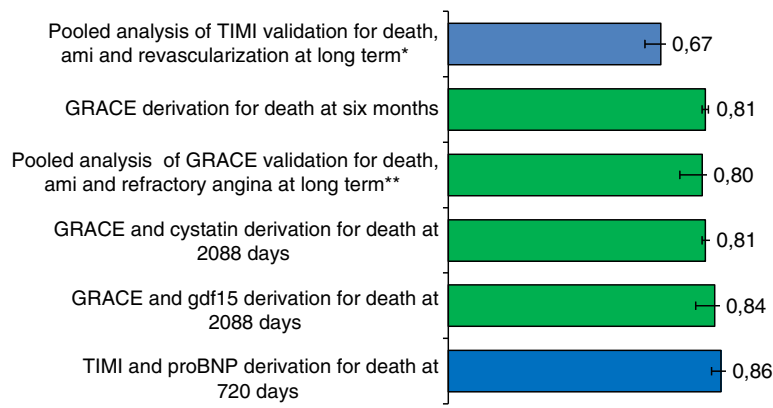

Fig. 4. Long term Area Under the Curve for derivation and validation scores of UA/ NSTEMI. For scores other than TIMI and GRACE, only those with a performance better or equal than the latter were reported. (*360 days (315-361); ** 180 days $(180-360))$. Heterogeneity for pooled results: $\mathrm{Tau}^{2}=0.00$; $\mathrm{Chi}^{2}=29.40, \mathrm{df}=5(P<0.0001) ; \mathrm{I}^{2}=83 \%$.

ACS and UA/NSTEMI studies, GRACE AUC is the highest in validation cohorts, both for evaluating short term outcomes and especially long term outcome which has been shown recently to be a challenge. [74] The only notable exception is the performance of TIMI with the addition of proBNP for long term outcome prediction in UA/STEMI [36], which performed better than GRACE. Another interesting finding is that some risk scores (both new scores and scores derived from TIMI with additional variables) show a comparable AUC to GRACE in their derivation cohorts, but without external validation their relevance is limited. For example, for studies evaluating ACS, the Schiele et al. [16] study and the Zhong et al. [15] study offer similar AUC to the AUC of Correia et al. [33] and AMIS [20] for UA/NSTEMI at short term. Interestingly only scores adding gdf15 or cystatin to GRACE [34] or pro-BNP to TIMI [36] perform similarly for patients with UA/NSTEMI. While the first two predictors may be difficult to exploit in everyday clinical practice, the latter could be very useful to guide management of these patients.

On the contrary, for STEMI patients many scores performed with similar AUC for both short term [54,59,62,65] and long term $[53,55,61,67,66]$ outcomes. If this is confirmed in validation studies, they could provide physicians a powerful tool to discriminate high risk patients. This is particularly true for more recently derived scores which include patients treated with the most modern medical and interventional strategies. There were several studies that performed poorly. The reason for this can only be guessed however maybe related to poor selection of patients or to statistical methodology.

The present work has several limitations. We considered only studies that had at least one analysis performed to assess incremental predictive ability. Many other articles reporting only risk factors without a clear evaluation of prediction were excluded, and it is important to remember that empirical evidence in other fields, for example cancer, suggest that new predictors are almost always significant [78]. Moreover, as suggested from visual inspection by funnel plot, no publication bias was reported. (Figure A, appendix, web only figure). Most of the included studies reported a low or moderate risk of selection and attrition bias, while attrition and adjudication were mostly appraised as moderate. (Table A, B and C, appendix, web only tables). Heterogeneity ranged from low to high, thus we performed our analysis with random effect methods; however we also used fixed models, with no effect on AUC.

Table 3

Baseline characteristics of STEMI studies

\begin{tabular}{|c|c|c|c|c|}
\hline & $\begin{array}{l}\text { Derivation studies } \\
\text { [53-67] (15 studies, } \\
134,457 \text { patients) }\end{array}$ & $\begin{array}{l}\text { TIMI validation studies } \\
{[18,20,33,46,57,60,61,68-72]} \\
\text { (12 studies, } 164,835 \text { patients) }\end{array}$ & $\begin{array}{l}\text { GRACE validation studies } \\
{[22,28,30,46,50,51,68,69]} \\
\text { (8 studies, } 12,204 \text { patients) }\end{array}$ & $\begin{array}{l}\text { Cadillac validation } \\
\text { studies }[68,69] \\
\text { ( } 2 \text { studies, } 1360 \text { patients) }\end{array}$ \\
\hline Patients & $2485(1412-9690)$ & $885(553-7520)$ & $602(456-1495)$ & $1033(900-1770)$ \\
\hline Male gender & $74(67-78)$ & $62(59-67)$ & $67.5(62-71)$ & $65.5(61.5-69)$ \\
\hline Age (years) & $62.5(62-66)$ & $64(61-67)$ & $65(61-69.5)$ & $67.5(62-69)$ \\
\hline Pts undergoing fibrinolysis & $100(0-100)$ & $15.5(0-64)$ & 0 & \\
\hline Pts undergoing PCI & $100(12-64)$ & $71(38-100)$ & $74.5(42.5-100)$ & - \\
\hline Pts undergoing PTCA & $31(25-64)$ & $60.5(30-72)$ & $71(58.6-71)$ & $36(29-39)$ \\
\hline Pts undergoing $\mathrm{CABG}$ & 21 & $6(3-9.7)$ & $9.1(8.1-10)$ & $6(3-9.7)$ \\
\hline Follow up (days) & $30(30-290)$ & $270(143-11)$ & $180(180-315)$ & $270(143-11)$ \\
\hline Mace & $5(5-10)$ & $5(3.5-4.5)$ & $3.7(3.3-5.5)$ & $5(3.5-4.5)$ \\
\hline Death & $6(4-7)$ & $7.5(7-12)$ & $6.7(6.3-14)$ & \\
\hline AMI & $3(2-4)$ & - & - & \\
\hline Revascularization & $13(12-20)$ & - & - & \\
\hline
\end{tabular}




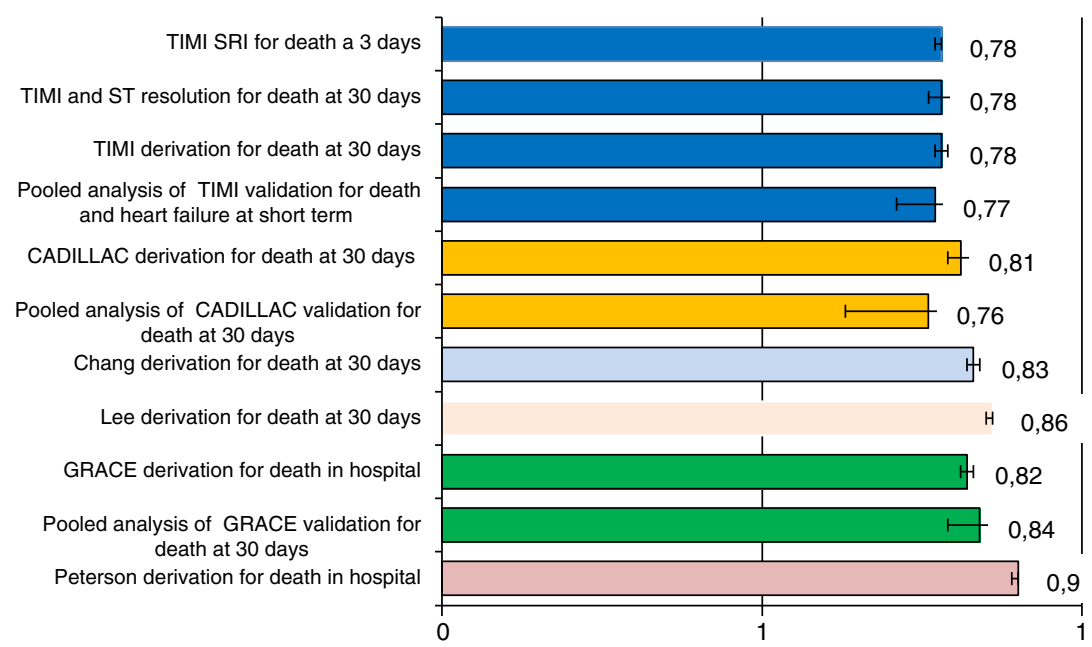

Fig. 5. Short term Area Under the Curve for derivation and validation scores of STEMI. For scores other than TIMI and GRACE, only those with a performance better or equal than the latter were reported. Heterogeneity for pooled results: Tau² $=0.00 ; \mathrm{Chi}^{2}=77.83, \mathrm{df}=5(P<0.00001) ; \mathrm{I}^{2}=94 \%$.

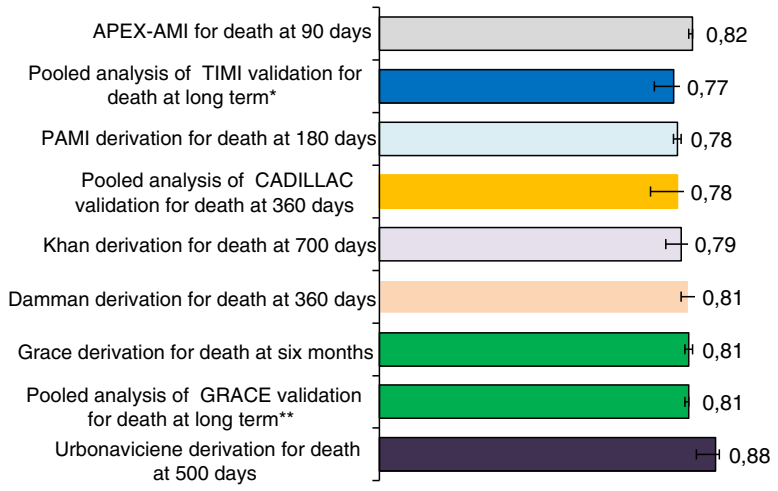

Fig. 6. Long term Area Under the Curve for derivation and validation scores of STEMI. For scores other than TIMI and GRACE, only those with a performance better than the latter were reported. (*360 days (225-360) **180 days $(180-360))$. Heterogeneity for pooled results: $\mathrm{Chi}^{2}=419.01$, $\mathrm{df}=6(P<0.00001) ; \mathrm{I}^{2}=99 \%$.

\section{Conclusions}

TIMI and GRACE are the risk scores that up until now have been most extensively investigated, with GRACE performing better. There are other potentially useful ACS risk scores available however these have not undergone rigorous validation. This study suggests that these other scores may be potentially useful and should be further researched.

\section{Disclosures}

None.

\section{Appendix A. Supplementary data}

Supplementary data to this article can be found online at doi:10.1016/j.cct.2012.01.001.

\section{References}

[1] Lee MS, Sillano D, Latib A, Chieffo A, Zoccai GB, Bhatia R, et al. Multicenter international registry of unprotected left main coronary artery percutaneous coronary intervention with drug-eluting stents in patients with myocardial infarction. Catheter Cardiovasc Interv 2009;73(1): 15-21.

[2] D'Ascenzo F, Gonella A, Quadri G, Longo G, Biondi-Zoccai G, Moretti C, et al. Comparison of mortality rates in women versus men presenting with ST-segment elevation myocardial infarction. Am J Cardiol 2011;107(5):651-4.

[3] Burzotta F, De Vita M, Gu YL, Isshiki T, Lefèvre T, Kaltoft A, et al. Clinical impact of thrombectomy in acute ST-elevation myocardial infarction: an individual patient-data pooled analysis of 11 trials. Eur Heart J 2009;30(18):2193-203.

[4] Granger CB, Goldberg RJ, Dabbous O, Pieper KS, Eagle KA, Cannon CP, et al. Global Registry of Acute Coronary Events Investigators.; Global Registry of Acute Coronary Events Investigators. Predictors of hospital mortality in the global registry of acute coronary events. Arch Intern Med 2003;163(19):2345-53.

[5] De Luca G, Biondi-Zoccai G, Marino P. Transferring patients with STsegment elevation myocardial infarction for mechanical reperfusion: a meta-regression analysis of randomized trials. Ann Emerg Med 2008;52(6):665-76.

[6] Biondi-Zoccai G, Lotrionte M, Agostoni P, Abbate A, Romagnoli E, Sangiorgi G, et al. Adjusted indirect comparison meta-analysis of prasugrel versus ticagrelor for patients with acute coronary syndromes. Int J Cardiol Sep. 72010 [Epub ahead of print].

[7] Antman EM, Cohen M, Bernink PJ, McCabe CH, Horacek T, Papuchis G, et al. The TIMI risk score for unstable angina/non-ST elevation MI: A method for prognostication and therapeutic decision making. JAMA 2000;284(7):835-42 16.

[8] Moher D, Cook DJ, Eastwood S, Olkin I, Rennie D, Stroup DF. Improving the quality of reports of meta-analyses of randomised controlled trials: the QUOROM statement. Quality of Reporting of Meta-analyses. Lancet 1999;354:1896-900.

[9] Moher D, Liberati A, Tetzlaff J, Altman DG, PRISMA Group. Preferred reporting items for systematic reviews and meta-analyses: the PRISMA statement. BMJ 2009;339:b2535.

[10] Moher D, Liberati A, Tetzlaff J, Altman DG, PRISMA Group. Meta-analysis of observational studies in epidemiology: a proposal for reporting. Meta-analysis of Observational Studies in Epidemiology (MOOSE) group. JAMA 2000;283:2008-12.

[11] The Cochrane Collaboration. In: Higgins JPT, Green S, editors. updated September 2009; 2009 Available from www.cochrane-handbook.org. (last accessed on January 2, 2011).

[12] Ramsay G, Podogrodzka M, McClure C, Fox KA. Risk prediction in patients presenting with suspected cardiac pain: the GRACE and TIMI risk scores versus clinical evaluation. QJM 2007;100(1):11-8. 
[13] Jaffery Z, Hudson MP, Jacobsen G, Nowak R, McCord J. Modified thrombolysis in myocardial infarction (TIMI) risk score to risk stratify patients in the emergency department with possible acute coronary syndrome. J Thromb Thrombolysis 2007;24(2): 137-44.

[14] Mahaffey KW, Yang Q, Pieper KS, Antman EM, White HD, Goodman SG, et al. SYNERGY Trial Investigators. Prediction of one-year survival in high-risk patients with acute coronary syndromes: results from the SYNERGY trial. J Gen Intern Med 2008;23(3):310-6.

[15] Zhong B, Liu Z, Su L, Lan X, Chen Y, Ling Z, et al. Comparison of prognostic value of different risk score methods on outcome of acute coronary syndrome. Clin Cardiol 2009;32(8):434-8

[16] Schiele F, Meneveau N, Seronde MF, Chopard R, Descotes-Genon V, Dutheil J, et al. Reseau de Cardiologie de Franche Comte. C-reactive protein improves risk prediction in patients with acute coronary syndromes. Eur Heart J 2010;31(3):290-7.

[17] Conway Morris A, Caesar D, Gray S, Gray A. TIMI risk score accurately risk stratifies patients with undifferentiated chest pain presenting to an emergency department. Heart 2006;92(9):1333-4.

[18] Filipiak KJ, Koltowski L, Grabowski M, Karpinski G, Glowczynska R, Huczek Z, et al. Prospective comparison of the 5 most popular risk scores in clinical use for unselected patients with acute coronary syndrome. Circ J 2010;75(1):167-73

[19] Jaffery Z, Hudson MP, Jacobsen G, Nowak R, McCord J. Modified thrombolysis in myocardial infarction (TIMI) risk score to risk stratify patients in the emergency department with possible acute coronary syndrome. J Thromb Thrombolysis 2007;24(2):137-44.

[20] Kurz DJ, Bernstein A, Hunt K, Radovanovic D, Erne P, Siudak Z, et al. Simple point-of-care risk stratification in acute coronary syndromes: the AMIS model. Heart 2009;95(8):662-8.

[21] Lyon R, Morris AC, Caesar D, Gray S, Gray A. Chest pain presenting to the Emergency Department-to stratify risk with GRACE or TIMI? Resuscitation 2007;74(1):90-3.

[22] Mahmoud WE, Hassanein MM, Nour El-Din MM, Elbeltagy SM, Sadaka MA. Validation of TIMI and GRACE Acute Coronary Risk Scores in Alexandria Governorate and their Role in the Comparison of Quality of Care between Hospitals. J Egypt Public Health Assoc 2010;85(1-2):1-28.

[23] Ramsay G, Podogrodzka M. McClure C, Fox KA. Risk prediction in patients presenting with suspected cardiac pain: the GRACE and TIMI risk scores versus clinical evaluation. OJM 2007;100(1):11-8 Epub 2006 Dec 15.

[24] Sanchis J, Bodí V, Núñez J, Bertomeu-González V, Gómez C, Bosch MJ, et al. New risk score for patients with acute chest pain, non-STsegment deviation, and normal troponin concentrations: a comparison with the TIMI risk score. J Am Coll Cardiol 2005;46(3):443-9.

[25] Eran O, Novack V, Gilutz H, Zahger D. Comparison of thrombolysis in myocardial infarction, global registry of acute coronary events, and acute physiology and chronic health evaluation II risk scores in patients with acute myocardial infarction who require mechanical ventilation for more than 24 hours. Am J Cardiol 2011:107(3):343-6.

[26] Abu-Assi E, Ferreira-González I, Ribera A, Marsal JR, Cascant P, Heras M, et al. Do GRACE (Global Registry of Acute Coronary events) risk scores still maintain their performance for predicting mortality in the era of contemporary management of acute coronary syndromes? Am Heart J 2010;160(5):826-34 e1-3.

[27] Alter DA, Venkatesh V, Chong A, SESAMI Study Group. Evaluating the performance of the Global Registry of Acute Coronary Events riskadjustment index across socioeconomic strata among patients. Am Heart J Feb. 2006;151(2):323-31.

[28] Elbarouni B, Goodman SG, Yan RT, Welsh RC, Kornder JM, Deyoung JP, et al. Canadian Global Registry of Acute Coronary Events (GRACE/ GRACE(2)) Investigators. Validation of the Global Registry of Acute Coronary Event (GRACE) risk score for in-hospital mortality in patients with acute coronary syndrome in Canada. Am Heart J 2009;158(3): 392-9.

[29] Gale CP, Manda SO, Weston CF, Birkhead JS, Batin PD, Hall AS. Evaluation of risk scores for risk stratification of acute coronary syndromes in the Myocardial Infarction National Audit Project (MINAP) database. Heart 2009;95(3):221-7.

[30] Tang EW, Wong CK, Herbison P. Global Registry of Acute Coronary Events (GRACE) hospital discharge risk score accurately predicts longterm mortality post acute coronary syndrome. Am Heart J 2007;153(1): 29-35.

[31] Eagle KA, Lim MJ, Dabbous OH, Pieper KS, Goldberg RJ, Van de Werf F, et al. GRACE Investigators. A validated prediction model for all forms of acute coronary syndrome: estimating the risk of 6 -month postdischarge death in an international registry. JAMA 2004;291(22):2727-33.

[32] Beygui F, Silvain J, Pena A, Bellemain-Appaix A, Collet JP, Drexler H, et al. Usefulness of biomarker strategy to improve GRACE score's prediction performance in patients with non-ST-segment elevation acute coronary syndrome and low event rates. Am J Cardiol 2010;106(5):650-8.
[33] Correia LC, Lima JC, Rocha MS, D'Oliveira Junior A, Péricles Esteves J. Does high-sensitivity C-reactive protein add prognostic value to the TIMI-Risk Score in individuals with non-ST elevation acute coronary syndromes? Clin Chim Acta 2007;375(1-2):124-8.

[34] Eggers KM, Kempf T, Venge P, Wallentin L, Wollert KC, Lindahl B. Improving long-term risk prediction in patients with acute chest pain: the Global Registry of Acute Coronary Events (GRACE) risk score is enhanced by selected nonnecrosis biomarkers. Am Heart J 2010;160(1):88-94.

[35] Body R, Carley S, McDowell G, Ferguson J, Mackway-Jones K. Can a modified thrombolysis in myocardial infarction risk score outperform the original for risk stratifying emergency department patients with chest pain? Emerg Med J 2009;26(2):95-9.

[36] Jarai R, Iordanova N, Jarai R, Jarai F, Raffetseder A, Woloszczuk W, et al. Prediction of clinical outcome in patients with non-ST-elevation acute coronary syndrome (NSTE-A.C.S.) using the TIMI risk score extended by $\mathrm{N}$-terminal pro-brain natriuretic peptide levels. Wien Klin Wochenschr 2007;119(21-22):626-32.

[37] Lagerqvist B, Diderholm E, Lindahl B, Husted S, Kontny F, Ståhle E, et al. FRISC score for selection of patients for an early invasive treatment strategy in unstable coronary artery disease. Heart 2005;91(8):1047-52.

[38] Boersma E, Pieper KS, Steyerberg EW, Wilcox RG, Chang WC, Lee KL, et al. Predictors of outcome in patients with acute coronary syndromes without persistent ST-segment elevation. Results from an international trial of 9461 patients. The PURSUIT Investigators. Circulation 2000;101(22):2557-67.

[39] Jiménez-Candil J, González Matas JM, Cruz González I, Hernández Hernández J, Martín A, Pabón P, et al. In-hospital prognosis in non-STsegment elevation acute coronary syndrome derived using a new risk score based on electrocardiographic parameters obtained at admission. Rev Esp Cardiol 2010;63(7):851-5.

[40] Kim HK, Jeong MH, Ahn Y, Kim JH, Chae SC, Kim YJ, et al. A new risk score system for the assessment of clinical outcomes in patients with non-ST-segment elevation myocardial infarction. Int J Cardiol 2010;145(3):450-4

[41] Piombo AC, Gagliardi JA, Guetta J, Fuselli J, Salzberg S, Fairman E, et al. A new scoring system to stratify risk in unstable angina. BMC Cardiovasc Disord 2003;3(8) Epub 2003 Aug 20

[42] Sanchis J, Bodí V, Núñez J, Bertomeu-González V, Gómez C, Bosch MJ, et al. New risk score for patients with acute chest pain, non-STsegment deviation, and normal troponin concentrations: a comparison with the TIMI risk score. J Am Coll Cardiol 2005;46(3):443-9.

[43] Solomon DH, Stone PH, Glynn RJ, Ganz DA, Gibson CM, Tracy R, et al. Use of risk stratification to identify patients with unstable angina likeliest to benefit from an invasive versus conservative management strategy. J Am Coll Cardiol 2001;38(4):969-76.

[44] Santos ES, Timerman A, Baltar VT, Castillo MT, Pereira MP, Minuzzo L, et al. Dante Pazzanese risk score for non-st-segment elevation acute coronary syndrome. Arq Bras Cardiol 2009;93(4):343-51 336-44.

[45] Bodí V, Sanchis J, Llàcer A, Fácila L, Núñez J, Pellicer M, et al. Multimarker risk strategy for predicting 1-month and 1-year major events in non-ST-elevation acute coronary syndromes. Am Heart J 2005;149(2): 268-74.

[46] Aragam KG, Tamhane UU, Kline-Rogers E, Li J, Fox KA, Goodman SG, et al. Does simplicity compromise accuracy in A.C.S. risk prediction? A retrospective analysis of the TIMI and GRACE risk scores. PLoS One 2009:4(11):e7947 23.

[47] Hess EP, Perry JJ, Calder LA, Thiruganasambandamoorthy V, Body R, Jaffe A, et al. Prospective validation of a modified thrombolysis in myocardial infarction risk score in emergency department patients with chest pain and possible acute coronary syndrome. Acad Emerg Med 2010;17(4):368-75.

[48] Tong KL, Kaul S, Wang XQ Rinkevich D, Kalvaitis S, Belcik T, et al. Myocardial contrast echocardiography versus Thrombolysis In Myocardial Infarction score in patients presenting to the emergency department with chest pain and a nondiagnostic electrocardiogram. J Am Coll Cardiol 2005;46(5):920-7 6.

[49] Yan AT, Yan RT, Tan M, Casanova A, Labinaz M, Sridhar K, et al. Risk scores for risk stratification in acute coronary syndromes: useful but simpler is not necessarily better. Eur Heart J 2007:28(9):1072-8.

[50] Bradshaw PJ, Ko DT, Newman AM, Donovan LR, Tu JV. Validity of the GRACE (Global Registry of Acute Coronary Events) acute coronary syndrome prediction model for six month post-discharge death in an independent data set. Heart 2006;92(7):905-9.

[51] Abu-Assi E, García-Acuña JM, Peña-Gil C, González-Juanatey JR. Validation of the GRACE risk score for predicting death within 6 months of follow-up in a contemporary cohort of patients with acute coronary syndrome. Rev Esp Cardiol 2010;63(6):640-8.

[52] Brilakis ES, Wright RS, Kopecky SL, Mavrogiorgos NC, Reeder GS, Rihal CS, et al. Association of the PURSUIT risk score with predischarge 
ejection fraction, angiographic severity of coronary artery disease, and mortality in a nonselected, community-based population with nonST-elevation acute myocardial infarction. Am Heart J 2003;146(5): 811-8.

[53] Addala S, Grines CL, Dixon SR, Stone GW, Boura JA, Ochoa AB, et al. Predicting mortality in patients with ST-elevation myocardial infarction treated with primary percutaneous coronary intervention (PAMI risk score). Am J Cardiol 2004;93(5):629-32 1.

[54] Chang WC, Kaul P, Fu Y, Westerhout CM, Granger CB, Mahaffey KW, et al. ASSENT-3 Investigators.; ASSENT-3 Investigators. Forecasting mortality: dynamic assessment of risk in ST-segment elevation acute myocardial infarction. Eur Heart J 2006;27(4):419-26.

[55] Damman P, Beijk MA, Kuijt WJ, Verouden NJ, van Geloven N, Henriques $\mathrm{JP}$, et al. Multiple biomarkers at admission significantly improve the prediction of mortality in patients undergoing primary percutaneous coronary intervention for acute ST-segment elevation myocardial infarction. J Am Coll Cardiol 2010;57(1):29-36 28.

[56] De Luca G, Suryapranata H, van 't Hof AW, de Boer MJ, Hoorntje JC, Dambrink JH, et al. Prognostic assessment of patients with acute myocardial infarction treated with primary angioplasty: implications for early discharge. Circulation 2004;109(22):2737-43 8.

[57] Dominguez-Rodriguez A, Abreu-Gonzalez P, Jimenez-Sosa A, Samimi-Fard $\mathrm{S}$, Idaira HB. Does ischemia-modified albumin add prognostic value to the Thrombolysis In Myocardial Infarction risk score in patients with STsegment elevation myocardial infarction treated with primary angioplasty? Biomarkers 2009;14(1):43-8.

[58] Dorsch MF, Lawrance RA, Sapsford RJ, Oldham J, Greenwood DC, Jackson $\mathrm{BM}$, et al. A simple benchmark for evaluating quality of care of patients following acute myocardial infarction. Heart 2001;86(2):150-4.

[59] Halkin A, Singh M, Nikolsky E, Grines CL, Tcheng JE, Garcia E, et al. Prediction of mortality after primary percutaneous coronary intervention for acute myocardial infarction: the CADILLAC risk score. J Am Coll Cardiol 2005;45(9):1397-405 3.

[60] Harkness JR, Sabatine MS, Braunwald E, Morrow DA, Sloan S, Wiviott SD, et al. Extent of ST-segment resolution after fibrinolysis adds improved risk stratification to clinical risk score for ST-segment elevation myocardial infarction. Am Heart J 2010;159(1):55-62.

[61] Khan SQ, Quinn P, Davies JE, Ng LL. N-terminal pro-B-type natriuretic peptide is better than TIMI risk score at predicting death after acute myocardial infarction. Heart 2008;94(1):40-3 Epub 2007 May 8.

[62] Lee KL, Woodlief LH, Topol EJ, Weaver WD, Betriu A, Col J, et al. Predictors of 30-day mortality in the era of reperfusion for acute myocardial infarction. Results from an international trial of 41,021 patients. GUSTO-I Investigators. Circulation 1995;91(6):1659-68 15.

[63] Morrow DA, Antman EM, Giugliano RP, Cairns R, Charlesworth A Murphy SA, et al. A simple risk index for rapid initial triage of patients with ST-elevation myocardial infarction: an InTIME II substudy. Lancet 2001;358(9293):1571-5 10.

[64] Morrow DA, Antman EM, Charlesworth A, Cairns R, Murphy SA, de Lemos JA, et al. TIMI risk score for ST-elevation myocardial infarction: A convenient, bedside, clinical score for risk assessment at presentation: An intravenous nPA for treatment of infarcting myocardium early II trial substudy. Circulation 2000;102(17):2031-7 24.

[65] Peterson ED, Dai D, DeLong ER, Brennan JM, Singh M, Rao SV, et al. NCDR Registry Participants.NCDR Registry Participants. Contemporary mortality risk prediction for percutaneous coronary intervention: results from 588,398 procedures in the National Cardiovascular Data Registry. J Am Coll Cardiol 2010;55(18):1923-32 4.
[66] Stebbins A, Mehta RH, Armstrong PW, Lee KL, Hamm C, Van de Werf F, et al. Assessment of Pexelizumab in Acute Myocardial Infarction (APEX AMI Investigators). Assessment of Pexelizumab in Acute Myocardial Infarction (APEX AMI Investigators). A model for predicting mortality in acute ST-segment elevation myocardial infarction treated with primary percutaneous coronary intervention: results from the Assessment of Pexelizumab in Acute Myocardial Infarction Trial. Circ Cardiovasc Interv 2010;3(5):414-22.

[67] Urbonaviciene G, Urbonavicius S, Vorum H, Bluzaite I, Jarusevicius G, Honoré B, et al. Evaluation of prognostic clinical and ECG parameters in patients after myocardial infarction by applying logistic regression method. Pacing Clin Electrophysiol 2008;31(11):1391-8.

[68] Kozieradzka A, Kamiński KA, Maciorkowska D, Olszewska M, Dobrzycki S, Nowak K, et al. GRACE, TIMI, Zwolle and CADILLAC risk scores - Do they predict 5-year outcomes after ST-elevation myocardial infarction treated invasively? Int J Cardiol 2011;148(1):70-5 1.

[69] Lev EI, Kornowski R, Vaknin-Assa H, Porter A, Teplitsky I, Ben-Dor I, et al. Comparison of the predictive value of four different risk scores for outcomes of patients with ST-elevation acute myocardial infarction undergoing primary percutaneous coronary intervention. Am J Cardiol Jul. 1 2008;102(1):6-11 Epub 2008 May 28.

[70] Rathore SS, Weinfurt KP, Gross CP, Krumholz HM. Validity of a simple ST-elevation acute myocardial infarction risk index: are randomized trial prognostic estimates generalizable to elderly patients? Circulation 2003;107(6):811-6 18.

[71] Morrow DA, Antman EM, Parsons L, de Lemos JA, Cannon CP, Giugliano RP, et al. Application of the TIMI risk score for ST-elevation MI in the National Registry of Myocardial Infarction 3. JAMA 2001;286(11): 1356-9 19.

[72] Morrow DA, Antman EM, Murphy SA, Assmann SF, Giugliano RP, Cannon CP, et al. The Risk Score Profile: a novel approach to characterising the risk of populations enrolled in clinical studies. Eur Heart J 2004;25(13):1139-45.

[73] Kuklinska AM, Sobkowicz B, Mroczko B, Sawicki R, Musial WJ, Knapp M, et al. Prognostic significance of the admission plasma B-type natriuretic peptide measurement in patients with first ST-elevation myocardial infarction in comparison with C-reactive protein and TIMI risk score. Clin Chim Acta 2007;382(1-2):106-11 Epub 2007 Apr 12.

[74] Fox KA, Carruthers KF, Dunbar DR, Graham C, Manning JR, De Raedt H, et al. Underestimated and under-recognized: the late consequences of acute coronary syndrome (GRACE UK-Belgian Study). Eur Heart J 2010;31(22):2755-64

[75] Serrano LA, Hess EP, Bellolio MF, Murad MH, Montori VM, Erwin PJ, et al. Accuracy and quality of clinical decision rules for syncope in the emergency department: a systematic review and meta-analysis. Ann Emerg Med 2010;56(4):362-73 e1.

[76] Ito H, Nussbaum M, Hermiller JB, Hodes Z, Brodie B, Cheek B, et al. STENT Group. An integer based risk score for predicting 30-day major adverse cardiac or cerebrovascular events after percutaneous coronary intervention with drug-eluting stents: results from a large prospective multicentre registry, the STENT Group. EuroIntervention 2011;6(8): 942-8.

[77] http://painconsortium.nih.gov/symptomresearch/chapter_8/index.htm.

[78] Kyzas PA, Denaxa-Kyza D, Ioannidis JP. Almost all articles on cancer prognostic markers report statistically significant results. Eur J Cancer 2007;43(17):2559-79. 